\title{
Feeding of the probiotic bacterium Enterococcus faecium NCIMB 10415 differentially affects shedding of enteric viruses in pigs
}

Susanne Kreuzer ${ }^{1 *}{ }^{*}$, Patrycja Machnowska ${ }^{2 \dagger}$, Jens Aßmus ${ }^{1}$, Matthias Sieber ${ }^{3}$, Robert Pieper ${ }^{4}$, Michael FG Schmidt ${ }^{5}$, Gudrun A Brockmann ${ }^{1}$, Lydia Scharek-Tedin ${ }^{4}$ and Reimar Johne ${ }^{2}$

\begin{abstract}
Effects of probiotic bacteria on viral infections have been described previously. Here, two groups of sows and their piglets were fed with or without feed supplementation of the probiotic bacterium Enterococcus faecium NCIMB 10415. Shedding of enteric viruses naturally occurring in these pigs was analyzed by quantitative real-time RT-PCR. No differences between the groups were recorded for hepatitis E virus, encephalomyocarditis virus and norovirus. In contrast, astrovirus was exclusively detected in the non-supplemented control group. Rotavirus was shedded later and with lower amounts in the probiotic piglet group $(p<0.05)$; rotavirus-shedding piglets gained less weight than non-infected animals $(p<0.05)$. Serum titres of anti-rotavirus $\lg A$ and $\lg G$ antibodies were higher in piglets from the control group, whereas no difference was detected between sow groups. Phenotype analysis of immune cell antigens revealed significant differences of the CD4 and CD8 $(p<0.05)$ as well as CD8a and CD25 $(p<0.1) T$ cell populations of the probiotic supplemented group compared to the non-supplemented control group. In addition, differences were evident for CD21/MHCll-positive $(p<0.05)$ and IgM-positive $(p<0.1)$ B cell populations. The results indicate that probiotic bacteria could have effects on virus shedding in naturally infected pigs, which depend on the virus type. These effects seem to be caused by immunological changes; however, the distinct mechanism of action remains to be elucidated.
\end{abstract}

\section{Introduction}

Bacteria- and virus-induced gastrointestinal disorders are a common problem in piglets. Infections are often associated with insufficient maternal immune protection, poor hygiene conditions, environmental changes, weaning stress, and dietary changes after weaning. To decrease the risk of infectious diseases, in-feed antibiotics have been used for decades. Their ban in Europe in 2006 has increased attempts to identify alternatives such as prebiotics, probiotics, organic acids, trace elements and other feed additives. In pigs, probiotics such as Enterococcus faecium are commonly used. Some studies show positive effects of probiotics against microbial infections in pigs [1-4].

\footnotetext{
* Correspondence: Susanne.Kreuzer.1@agrar.hu-berlin.de

${ }^{\dagger}$ Equal contributors

${ }^{1}$ Breeding Biology and Molecular Genetics, Humboldt-Universität zu Berlin, Invalidenstraße 42, D-10115 Berlin, Germany

Full list of author information is available at the end of the article
}

No effective therapy exists against intestinal virus infections of pigs. Therefore, vaccination is the most promising method to actively control disease and viral shedding. However, vaccines are only available for a few viruses, whereas a wide range of viruses could be detected in porcine feces. Some of them are closely related to human viruses and are therefore supposed to have a zoonotic potential. This includes astrovirus (AstV), encephalomyocarditis virus (EMCV), hepatitis $\mathrm{E}$ virus (HEV), norovirus genogroup II (NoV GGII) and group A rotavirus (rotavirus A). The infections can be associated with diarrhoea. For example rotavirus A causes acute diarrhoea in weaning and post-weaning piglets as well as in children [5]. Natural infection with hepatitis $\mathrm{E}$ virus is subclinical in pigs but may cause disease in humans [6,7] whereas infection with EMCV is associated with myocarditis and reproductive failure in pigs $[8,9]$. The clinical significance of norovirus and astrovirus infection in pigs is unclear. Some studies

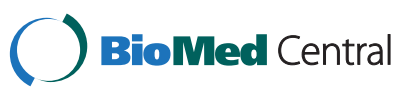


analyzed the effectiveness of probiotic treatment against virus-induced diarrhoea in humans. Child care infants fed with Lactobacillus reuteri or Bifidobacterium lactis had fewer and shorter episodes of diarrhoea [10]. In another study with children, the infection with rotavirus could not be prevented by the prophylactic use of probiotics; however, several strains of Lactobacillus turned out to significantly shorten the duration of diarrhoea $[11,12]$. Likewise, the diarrhoeal phase was shortened in adult humans with acute diarrhoea treated with Enterococcus (E.) faecium NCIMB 10415 [13].

Other studies report modulatory effects of probiotics on the intestinal mucosal immunity in piglets [14-16]. Only a few studies investigated the effects of probiotics on virus infections of pigs. For instance, piglets fed with Bifidobacterium lactis HN019 showed a reduced severity of naturally acquired diarrhoea during weaning [17]. This effect was associated with a lower amount of rotavirus and $E$. coli shed with the feces. Another study with gnotobiotic piglets experimentally infected with human rotavirus and colonized with Lactobacillus acidophilus and Lactobacillus reuteri showed no significantly reduced rotavirus shedding of diarrhoea [18]. The rotavirus-specific antibody and B cell response were similar for piglets treated with or without the probiotic bacteria. However, colonization with the probiotic bacteria resulted in a significantly higher titre of total serum IgM as well as intestinal IgM, IgG and IgA. No sows were included in this study. However, passively acquired maternal antibodies through feeding of colostrum play a major role in prevention of rotavirus disease in piglets [19]. Infection of the sows via contact to infected animals and feces lowers the risk of the piglets for rotavirus diarrhoea, but only during the first two weeks of life [20]. Thereafter, the risk for piglet diarrhoea rises independently of the sows' immune status. As viral shedding by the sows continues, piglets are vulnerable during this phase, and probiotics may have a positive impact on their health status at this time-point. Studies with sows and piglets revealed that E. faecium NCIMB 10415 modulates the intestinal immune system [16]. However, the effects on bacterial infections were contradictive: on one hand, carry over infections of Chlamydia from the sows to their piglets were reduced [21] and infections with pathogenic $E$. coli were less frequent [16]. On the other hand, challenge infections with Salmonella Typhimurium DT104 were more severe in piglets fed with E. faecium than in the control group [22]. It was concluded that E. faecium alleviates only infections with pathogenic germs that are already established in the herd. According to this thesis, the immunity of the sows and the passive immune protection of their piglets are considered as important factors, which are affected by probiotic bacteria.
To test, whether feeding of E. faecium NCIMB 10415 to sows and their piglets has an impact on naturally occurring enteric viral infections, we performed a feeding trial and monitored the shedding of enteric viruses. In order to gain insight into the mechanisms of action of probiotic bacteria, changes in the intestinal mucosal immune system of the piglets as well as the systemic immune system of the sows and their piglets were investigated in more detail.

\section{Materials and methods}

\section{Animals, housing and feeding}

The study was approved by the local state office of occupational health and technical safety "Landesamt für Gesundheit und Soziales Berlin" (LaGeSo Reg. Nr. 0347/09).

Sixteen pregnant purebred landrace sows were randomly allocated into either control $(C, n=8)$ or probiotic treatment $(P, n=8)$. Sows in the probiotic group were fed a diet with 4.2 to $4.3 \times 10^{6} \mathrm{cfu} / \mathrm{g}$ Enterococcus faecium (E. faecium)NCIMB 10415 (Cylactin ${ }^{\circledR}$, CerbiosPharma SA, Lugano, Switzerland) from 28 days ante partum (a.p.) onwards. Among the 16 sows 12 had 10 to 13 piglets per litter and were therefore used for the experiment. In both control and E. faecium fed groups were six sows. All animals were kept under similar conditions but in different buildings in order to prevent probiotic cross contamination. Seven days after birth, four animals per litter ( 2 male, 2 female) were randomly chosen and ear tagged for later tissue sampling of one piglet of every litter at four different time points. Piglets were kept with their dams until weaning at the age of $26 \pm 2$ days. After weaning, piglets were kept in commercial flatdeck pens with two animals per pen until 54 days of age. From the age of 12 days on, piglets had access to a non-medicated pre-starter diet. After weaning they were fed a starter diet. The starter diets of the probiotic supplemented group contained $5.1 \times 10^{6} \mathrm{cfu} / \mathrm{g}$ (prestarter) and $3.6 \times 10^{6} \mathrm{cfu} / \mathrm{g}$ (starter) of E. faecium NCIMB 10415.

\section{Sampling and tissue preparation}

One ear tagged piglet from each litter was euthanized for blood and tissue sampling at the age of $12 \pm 1(n=6)$, $26 \pm 1(n=6), 34 \pm 1(n=7)$ and $54 \pm 2(n=8)$. Therefore, at each time point six animals ( 3 males, 3 females) were used per feeding group. Additionally, at day 34 one piglet and at day 54 two piglets more per feeding group were sampled as described previously [23]. Blood was taken via cardiac puncture under ketamine/azaperone anesthesia (4 mg/kg; $25 \mathrm{mg} / \mathrm{kg}$ bodyweight) to isolate immune cells (see below) and to prepare a hemogram for counting of immune cells per $\mathrm{mL}$ microscopically. Piglets were then euthanized by intracardial injection of a lethal dose of tetracaine hydrochloride, mebezonium 
iodide and embutramide (T61, Intervet, Unterschleißheim, Germany). Following a midline abdominal incision, the small intestine was dissected from the large intestine at the ileo-cecal junction and both segments were dissected from the mesentery. A $2 \mathrm{~cm}$ long distal part of continuous Peyer's Patch from the ileum (IL PP) and discrete Peyer's Patches from mid jejunum (Je PP) were collected in Hank's Buffered Salt Solution (HBSS). Lymph nodes (LN) of the jejunum (Je LN) and ileum (IL $\mathrm{LN}$ ) were collected in $15 \mathrm{~mL}$ Falcon tubes filled with $5 \mathrm{~mL}$ phosphate buffered saline containing $0.2 \%$ bovine serum albumin (PBS/BSA). Feces for virus detection were collected from each piglet at the sampling time point. In addition, feces and serum samples were taken from each sow at days 28 and 7 a.p.

\section{Immune cell isolation}

The isolation of immune cells from blood, discrete PP and continuous PP were carried out as described previously [22]. Cells were collected after passage through either a nylon mesh or pressed with a syringe piston through a $70 \mu \mathrm{m}$ BD Cell Strainer, and flushed with PBS/BSA, to remove the connective and fat tissues. The lymphocytes and the peripheral blood mononuclear cells (PBMC) were further purified using centrifugation in a Ficoll gradient. After final lysis of erythrocytes for $5 \mathrm{~min}$ on ice in Erylyse-Puffer pH 7.2 - 7.4 (Morphisto $\mathrm{GmbH})$, the immune cells were washed with $10 \mathrm{~mL}$ of PBS/BSA and centrifuged for $15 \mathrm{~min}$ at $390 \times g$ at $4^{\circ} \mathrm{C}$.

\section{Flow cytometry}

Combinations of monoclonal antibodies against surface antigens were used to detect following cell types: $\mathrm{T}$ helper cells $\left(\mathrm{CD}^{+}, \mathrm{CD} 25^{+/-}, \mathrm{CD} 8^{-/ \text {dim }}\right)$, cytotoxic T cells $(\mathrm{CD} 8 \alpha /$ $\left.\beta^{+}, \mathrm{CD} 4^{-}\right)$, and $\mathrm{B}$ cells $\left(\mathrm{CD} 21^{+} / \mathrm{MHCII}^{+}\right.$or membrane$\left.\operatorname{IgM}^{+}\right)$. Staining of purified immune cell preparations for $\mathrm{CD} 4 \alpha$ and $\mathrm{CD} 8 \alpha$ were performed with labeled primary antibodies in a one step-incubation as described before [24]. Other immune cell surface markers CD8 $\beta$, CD25, CD21, IgM were detected using unlabelled primary antibodies (Additional file 1: Table S1) After washing, cells were incubated for 15 min with subclass specific secondary antibodies (goat anti-mouse-IgG, conjugated to Fluorescein isothiocyanate (FITC), R-Phycoerythrin (PE) or Allophycocyanin (APC) (Additional file 1: Table S1). After a second wash, cells were resuspended in $1 \mathrm{~mL}$ of PBS/ BSA. Propidium iodide (PI) $(0.5 \mu \mathrm{g} / \mathrm{mL})$ was added to each sample directly prior to measurement, and 40000 living $\left(\mathrm{PI}^{-}\right)$lymphocytes per sample were assayed by flow cytometry (FCM) within the lymphocyte gate corresponding to their forward light and sideward light scatter signals using a FACSCalibur flow cytometer equipped with a $488 \mathrm{~nm}$ argon laser and a $635 \mathrm{~nm}$ red diode laser (Becton Dickinson, Heidelberg, Germany).
RNA extraction and real-time RT-PCR for virus detection A $10 \%$ (wt/vol) faecal suspension was prepared with PBS and clarified by centrifugation at $1700 \times g$ for $15 \mathrm{~min}$ at $4^{\circ} \mathrm{C}$. Viral RNA was extracted from $140 \mu \mathrm{L}$ of the suspension using the QIAamp viral RNA mini kit (Qiagen, Hilden, Germany) according to the manufacturer's instructions. The RNA was eluted in $60 \mu \mathrm{L}$ buffer AVE (Qiagen, Hilden, Germany) and stored at $-80^{\circ} \mathrm{C}$ until use. Real-time RT-PCRs were performed in an ABI PRISM 7500 cycler (Applied Biosystems, Darmstadt, Germany) using the Quantitect Probe RT-PCR Kit (Qiagen, Hilden, Germany). The sequences of the used primers and TaqMan probes are listed in Additional file 2: Table S2. Primers and probes for the detection of $\mathrm{HEV}$, rotavirus $\mathrm{A}$ and NoV GGII as well as cycling conditions were used as described elsewhere [25-27]. Slight modifications are indicated in Additional file 2: Table S2. A comparison of published primers and probe sequences for the detection of murine mengovirus [28] with sequence data of porcine EMCVs (GenBank) indicated that murine primers are suitable to detect porcine EMCVs. Real-time RT-PCRs were carried out in $25 \mu \mathrm{L}$ of reaction mixture containing $600 \mathrm{nM}$ of each primer, $150 \mathrm{nM}$ probe and $5 \mu \mathrm{L}$ of the extracted RNA. After reverse transcription at $55^{\circ} \mathrm{C}$ for $60 \mathrm{~min}$, an initial denaturation step at $95^{\circ} \mathrm{C}$ was performed for $5 \mathrm{~min}$, followed by 45 cycles of amplification with denaturation at $95^{\circ} \mathrm{C}$ for $15 \mathrm{~s}$, annealing at $60^{\circ} \mathrm{C}$ for $1 \mathrm{~min}$ and elongation at $65^{\circ} \mathrm{C}$ for $1 \mathrm{~min}$. In order to detect a wide range of different astroviruses, two reverse primers and two probes were designed based on multiple alignments with astrovirus sequences from database (GenBank). The respective real-time RT-PCR was carried out using 750 $\mathrm{nM}$ of forward primer Mon 244 [29], $750 \mathrm{nM}$ of each reverse primer, $200 \mathrm{nM}$ of each probe and $5 \mu \mathrm{L}$ of the extracted RNA. The cycling conditions were: $60 \mathrm{~min}$ at $42^{\circ} \mathrm{C}$ for reverse transcription and $15 \mathrm{~min}$ at $95^{\circ} \mathrm{C}$ for initial denaturation, followed by 45 cycles of amplification with denaturation at $94^{\circ} \mathrm{C}$ for $30 \mathrm{~s}$, annealing at $50^{\circ} \mathrm{C}$ for $30 \mathrm{~s}$ and extension at $72^{\circ} \mathrm{C}$ for $1 \mathrm{~min}$. To determine $\mathrm{R}^{2}$ value, PCR-efficiency and sensitivity for each assay, standard curves were generated using a series of ten-fold dilutions of the RNA standard (see below) ranging from $10^{-1}$ to $10^{13}$ RNA molecules per reaction. All assays turned out to be linear over a range of nine logs and have $R^{2}$ values of 0.99. PCR-efficiency was calculated from the slope of the standard curve and ranged from 91\% (HEV) to $102 \%$ (AstV).

\section{Quantification of genome equivalent numbers}

RNA-standards were generated by cloning of the RTPCR products and subsequent in vitro transcription as described elsewhere [30]. Briefly, viral target regions were amplified by conventional RT-PCR using the Qiagen One Step RT-PCR kit (Qiagen, Hilden, Germany) 
with primers and cycling conditions as described above, but without probes. After cloning into the pCR4-TOPO vector using the TOPO TA Cloning Kit for Sequencing (Invitrogen, Karlsruhe, Germany), inserts containing a flanking T7 promotor were amplified by PCR with primers M13F and M13R (Invitrogen, Karlsruhe, Germany). Resulting PCR products were purified with the QIAquick DNA purification Kit (Qiagen, Hilden, Germany) and transcribed in vitro using the MEGAscript T7 Kit (Applied Biosystems, Darmstadt, Germany) according to the manufacturer's instructions. After a DNase I digestion step, in vitro transcripts were purified with the High Pure RNA Isolation Kit (Roche, Mannheim, Germany) and the RNA was stored at $-80^{\circ} \mathrm{C}$. The concentration of RNA was photo metrically measured by NanoDrop device (Thermo Fisher Scientific, Bonn, Germany) and used to calculate the number of RNA molecules per $\mu \mathrm{L}$. Tenfold dilutions series of these RNA standards were used in quantitative real-time RT-PCRs for determination of genome equivalent numbers.

\section{ELISA for rotavirus A-specific antibodies}

A total of 52 serum samples derived from 52 piglets at $12 \mathrm{~d}, 26 \mathrm{~d}, 34 \mathrm{~d}$ and $54 \mathrm{~d}$ and 24 serum samples at time points $28 \mathrm{~d}$ and 7 a.p. from 12 sows were tested for the presence of porcine anti-rotavirus A IgG and IgA antibodies using the Ingezim rotavirus porcine ELISA Kit (INGENASA, Madrid, Spain). The ELISA was performed as described in the manufacturer's instructions. For the detection of anti-rotavirus A IgA antibodies, the ELISA was performed analogically, but the secondary antibody was exchanged by peroxidise-labelled goat anti-porcine IgA (Thermo Fisher Scientific, Bonn, Germany) at a dilution of $1 / 10000$. The absorbance of each sample was measured at $450 \mathrm{~nm}$. The cut-off value for anti-rotavirus A IgG antibodies was derived from the manufacturer's instructions. As it was assumed that anti-rotavirus A IgA antibodies are derived from sows only via colostrum, the cut-off value was defined on the basal values determined for sera of the piglets derived from late timepoints. Therefore, for the determination of the cut-off value, the average value of the absorbance of all sera from days 34 and 54 was calculated, the standard deviation was doubled and added to the average. Normalized OD450 values were calculated by subtraction of the cutoff value from the respective OD450 value of the sample. Normalized OD450 values $>0$ were considered positive and normalized OD values $\leq 0$ were considered negative (negative OD450 values are not shown in Figure 1).

\section{Statistical analysis}

Statistical analysis was performed using $\mathrm{R} 2.11 .1$ and SPSS 12.0.2. (SPSS, Inc., Chicago, IL, USA). All values higher than 2-times the interquartiles range below the $1^{\text {st }}$ quartile and above the $3^{\text {rd }}$ quartile were identified as outliers (less than 1\% of all data). All outliers were then removed from subsequent analyses. The data were analyzed applying the general linear model and the ShapiroWilk test for determination of the normal distribution. Since all data were nearly normally distributed, we used raw data for the statistical tests Paired $\mathrm{T}$ test was performed to elucidate the effects of the feeding group. Analysis of variance (ANOVA) was performed to detect factors influencing the relative cell count of immune cells, virus shedding, and immune globulins in serum. The effects of tissue (four classes: blood, ileum lymph node, jejunum lymph node, ileal Peyers patch), age of piglets (four classes: 12, 26, 34 and 54 days of age), feeding group (two classes: feed supplemented with $E$. faecium or not), sex (two classes) and interaction of age of piglets $\mathrm{x}$ feeding group were tested (nominal co-variates); sow identity was considered as a random effect. Differences were considered significant at $p<0.05$. Boxwhisker plots were chosen for graphical presentation of the results. The boxes indicate the medians (horizontal lines) and the lower and upper quartiles (lower and upper sides of the boxes). Also a Wilcoxon rank-sum test and a chi-squared test were applied to test if the numbers of shedded viruses were affected by E. faecium.

\section{Results}

\section{Animal health status and performance}

The sows did not show obvious clinical signs during the whole experiment. A few piglets from both groups had signs of diarrhoea showing liquid stool with a minor proportion of formed particles after weaning.

\section{Shedding of enteric viruses}

The real-time RT-PCR tests were successfully developed for the quantitative detection of pig enteric viruses. The tests were sensitive to detect from up to 45 copies for AstV, 20 copies for EMCV, 68 copies for HEV, 78 copies for NoV GGII and 15 copies for rotavirus A. All viruses were detected in at least one of the groups (Figure 2). HEV was detected only in sows, whereas EMCV and NoV GGII were detected exclusively in piglets. No correlation was evident between virus detection and membership to the control or probiotic group for HEV, EMCV, and NoV GGII (Figure 2a-c). For AstV, nine piglets and two sows were tested positive, all animals belonging exclusively to the control group (Figure 2d). Statistical analysis indicated that the difference of astrovirus detection between the groups was highly significant $(p<0.001)$. Rotavirus A was detected in both the control and the probiotic group. At 28 days a.p., rotavirus A was detected in sows of the probiotic as well as the control group indicating that the virus was present in both groups at the beginning of the experiment. However, piglets belonging to the control 


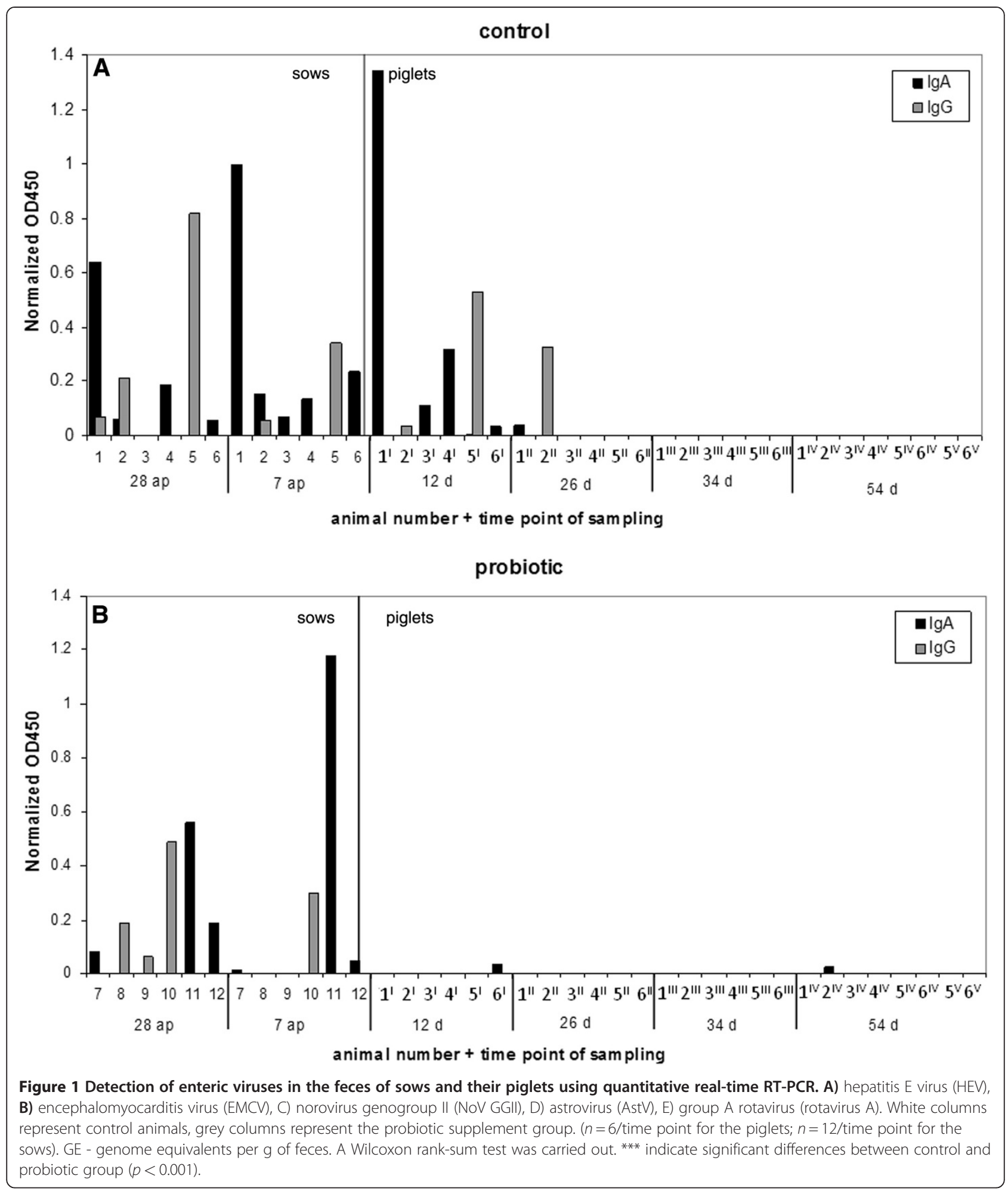

group are more often infected by rotavirus A than piglets with $E$. faecium supplementation $(p=0.064)$. Altogether, 8 piglets were infected by rotavirus. In the group of infected piglets, the amount of rotavirus in the feces was two orders of magnitude lower in the probiotic group than in the control group $(p=0.042)$. Moreover, shedding of rotavirus A occurred later $(p=0.035)$ in the E. faecium supplemented group (Figure 2e). Analysis of the piglet growth indicates that piglets infected with rotavirus $\mathrm{A}$ (irrespective of E. faecium supplementation) gained 


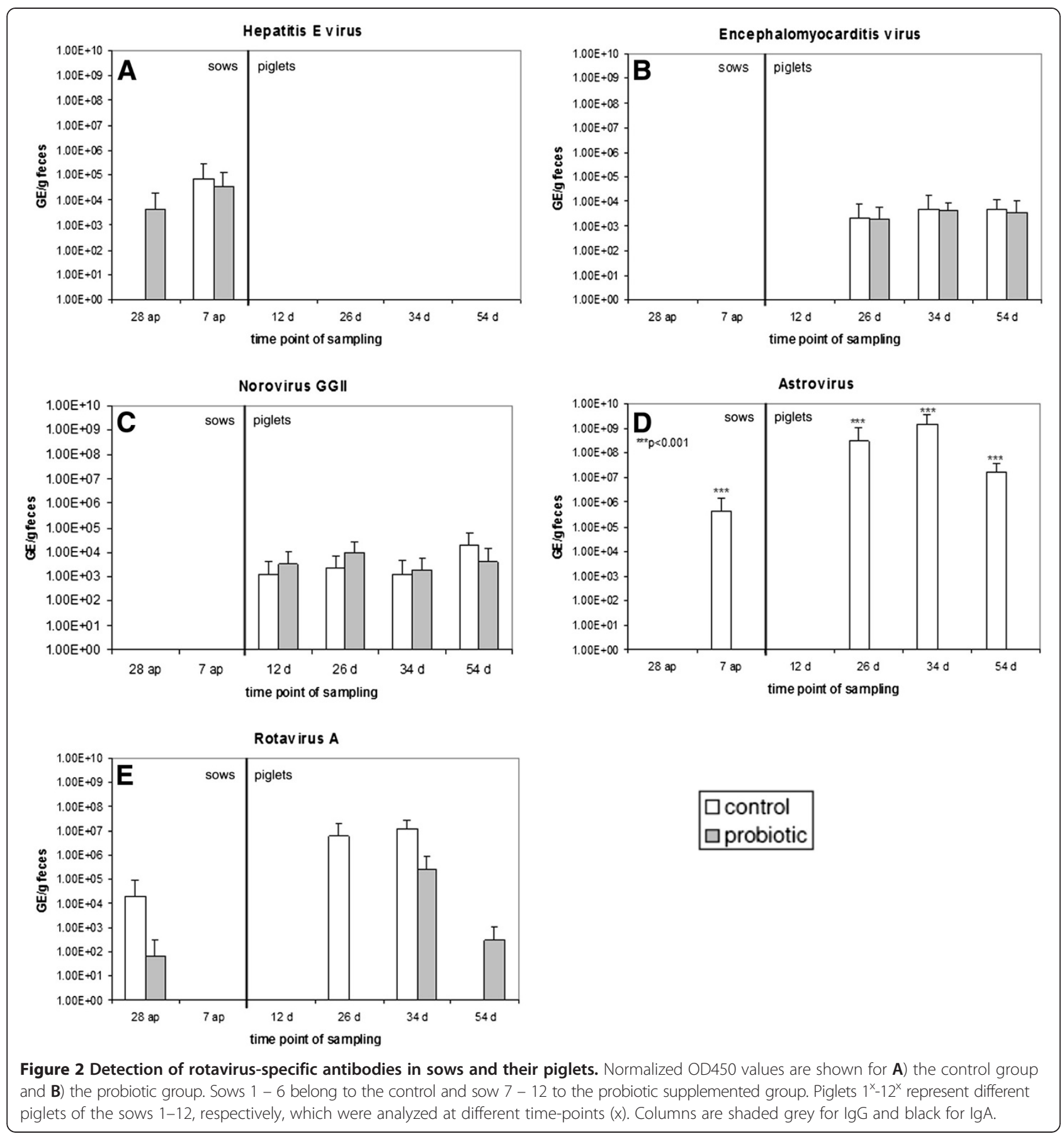

less weight $(p=0.014)$ than the non-infected animals (Additional file 3: Figure S1).

\section{Humoral immunity - anti-rotavirus A IgA and IgG}

Serum samples from sows and their piglets were tested for the presence of anti-rotavirus A IgG and IgA antibodies (Figure 1). Three sows of the control group and three sows of the probiotic group turned out to be positive for anti-rotavirus IgG antibodies, with decreasing titres between day 28 a.p. and day 7 a.p. Three piglets aged 12 and 26 days and belonging to the control group were tested positive for anti-rotavirus A IgG antibodies, whereas all piglets from the probiotic group turned out to be negative. Five sows of the control group and three sows of the probiotic group were positive for anti-rotavirus A IgA antibodies. In the control group, 
five piglets younger than 26 days where tested positive for anti-rotavirus A IgA, including one piglet with a high titre at 12 days of age. In the probiotic group, only two piglets (12 and 54 days old) were slightly positive for anti-rotavirus A IgA antibodies.

\section{Phenotyping of immune cell populations}

Immune cell populations were only phenotyped in the piglets. The flow cytometric analysis of piglet blood samples indicated, that the relative percentages of the $\mathrm{CD}_{21}{ }^{+} / \mathrm{MHCII}^{+}$double-positive $\mathrm{B}$ cell population were higher in piglets of the probiotic group compared to the control group at days 26 and 54 (Figure 3a). Additional measurements of the absolute leukocyte counts/l blood and calculated absolute changes of the different immune cell population in blood, show the same tendencies for the behaviour of the immune cells for the two feeding groups (Additional file 4: Figure S2). Interestingly, the opposite of the relative distribution of B cells occurred in tissue samples from the ileum lymph nodes, with lower frequency of B cells in the control group at days 26 and 54 (Figure $3 \mathrm{~b}$ ).

In the blood, $\mathrm{CD} 8 \beta^{+}$cytotoxic $\mathrm{T}$ cells were more frequent in the probiotic group at 11 days of age $(p<0.05)$; however, this effect was not apparent around weaning time (Figure 4). $\mathrm{CD}^{+} \mathrm{T}$ helper $\left(\mathrm{T}_{\mathrm{H}}\right)$ cells were characterized by $\mathrm{CD} 4^{+} \mathrm{CD} 8 \alpha^{-/ \operatorname{dim}}$ gating (Figure $5 \mathrm{a}$ ). All cells within this gate were further checked for their CD25 status and only $\mathrm{CD} 44^{+} \mathrm{CD} 8 \alpha^{-/ \operatorname{dim}} \mathrm{CD} 25^{\text {high }}$ cells were considered as $\mathrm{T}$ regulatory $\left(\mathrm{T}_{\text {reg }}\right.$ ) cells (Figure $5 \mathrm{~b}$ ). Some animals from selected time points were additionally tested for an intracellular antibody against Foxp3. We could confirm that basically all CD25high cells were also Foxp3 positive and ad versa (Additional file 5: Figure $\mathrm{S} 3$ ). Therefore only $\mathrm{T}$ regulatory $\left(\mathrm{T}_{\text {reg }}\right)$ cells were included in the analysis. In the ileal lymph nodes, the relative number of $\mathrm{CD} 4^{+} \mathrm{T}_{\mathrm{H}}$ cells was significantly $(p<0.05)$ increased in the probiotic group at day 54 (Figure 5c). In contrary, the percentage of $\mathrm{T}_{\text {regs }}$ was decreased at the same time-point (Figure 5d). In the ileal Peyer's Patches, a comparatively high number of $\mathrm{CD}^{+} \mathrm{T}$ helper cells were detectable for both groups at 12 days of age, whereas their frequency was low at later timepoints (Figure 5e). Out of these few $\mathrm{CD}^{+} \mathrm{T}$ helper cells, a considerable high percentage was identified as $\mathrm{T}_{\text {reg }}$ cells (Figure 5f). A more detailed description of the statistical results is presented in the Additional file 6: Tables S3 and 7: Table S4.

\section{Discussion}

Effects of probiotic bacteria on viral infections in humans and animals have been described previously $[11,12,17,18]$. Most of the data from pigs are derived
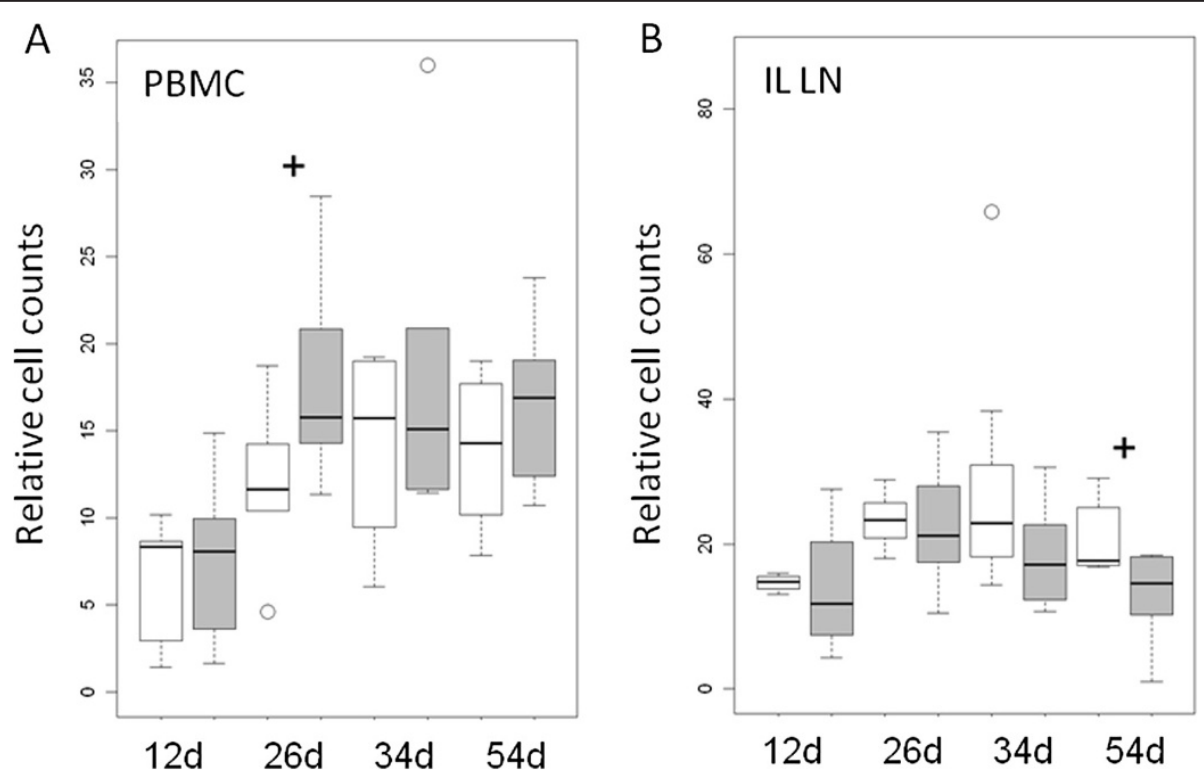

Figure 3 Relative cell counts of B cells in piglets of the probiotic ( $n=6$ per time point, grey boxes) and the control group ( $n=6$ per time point, white boxes) at different days of life. Cell counts are given as counts relative to the total number of gated living lymphocytes. A) B cells expressing $\mathrm{CD}_{21} \mathrm{~T}^{+} \mathrm{MHCI}{ }^{+}$in the peripheral blood mononuclear cell (PBMC) population. B) B cells expressing IgM on their cell surface present in ileal lymph nodes (IL LN). An ANOVA model revealed significant differences between the feeding groups $(p=0.043)$. A t-test was further performed for each age group and the results are shown $\left({ }^{+} 0.05<p<0.1\right)$. 


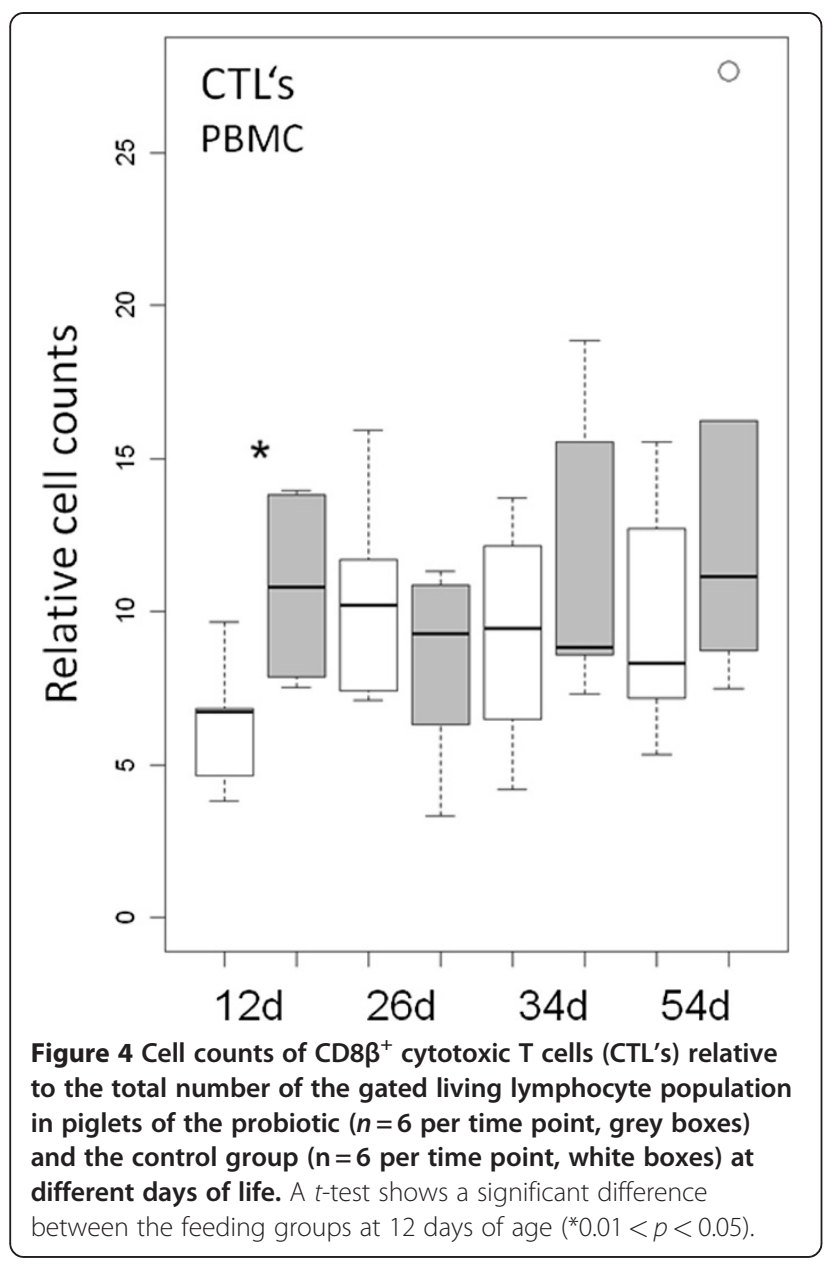

from experimental infection studies with pathogenic viruses [18,31,32]. However, only little is yet known about the effects on enteric viruses that occur naturally in pigs [17]. Here, two groups of sows and their piglets were fed with or without a supplementation of the probiotic bacterium Enterococcus faecium NCIMB 10415. By real-time RT-PCR analyses of the feces, the detection rates of enteric viruses differed between the probiotic and control group depending on the analyzed virus type. No differences between the groups were found for EMCV, HEV and NoV GGII. In contrast, astrovirus was detected only in the control group and rotavirus A was shed later and with lower amounts in the probiotic group. Although the reasons for the observed differences are not known so far, the results may indicate that probiotic bacteria are generally able to affect virus shedding in naturally infected pigs.

Recent studies have indicated that astroviruses (AstV) are highly prevalent in pigs [33,34]. But the clinical significance of AstV infection remains unclear. In our study, samples of nine piglets and two sows were tested positive for AstV, thus confirming the presence of this virus in the examined German landrace pig population. As the virus was exclusively found in the control group, an advantageous effect of the probiotic bacteria in prevention of AstV shedding may be postulated. However, it should be taken into account that the sows used in this study could only be naturally infected by AstV before the beginning of the experiment. Sows were randomly assigned to the groups and thereafter separated and kept in different buildings. Nevertheless, it cannot be totally excluded, that only animals of the control group had contact to AstV, while those of the probiotic group did not. Additional controlled experimental infection studies will be necessary to confirm the findings.

In contrast, rotavirus A was detected in both groups at the beginning of the experimental period. Therefore, it is likely that both groups had a similar exposure to rotavirus $\mathrm{A}$ and that the observed differences in rotavirus A shedding between the groups can be attributed to feeding with the probiotic bacterium. Positive effects of probiotics on the outcome of rotavirus disease in children have been described repeatedly [10-12,35]. Our findings in pigs are supported by published data, which indicate that an oral administration of another probiotic Bifidobacterium lactis HN019 could not only significantly reduce the severity of weanling diarrhoea, but also lower the concentration of rotavirus particles in the feces [17].

In order to gain insights into the possible mechanism of action of the probiotic feeding, the rotavirus Aspecific humoral immune response was examined. Shu et al. [17] found increases of pathogen-specific antibody titres in feces as well as a higher response of blood leukocyte and T-lymphocyte proliferation, indicating an immune-mediated process that would be responsible for the positive effect on the rotavirus infection. Different to other studies, an increase of serum anti-rotavirus A IgA or IgG antibodies in piglets from the probiotic group was not observed in our study. In contrast, the number of antibody-positive piglets and the respective antibody titres tended to be higher in the control group. However, antibody titres in the serum may not correlate with protection against rotavirus infection; and neutralizing rotavirus-specific IgA within the gut is considered as a more important protective factor [19]. Therefore, we also analyzed the presence of B cells within lymph nodes of the gut. We found in the tissue of ileal mesenteric lymph nodes that B cells were also less frequent in the probiotic group compared to the control group. Therefore, the observed protective effect on virus shedding by supplementation of E. faecium seems not to be caused by an enhancement of the humoral immunity.

Besides antibody-mediated effects, other possible mechanisms of action of the probiotic bacteria may be considered as for example competitive receptor 

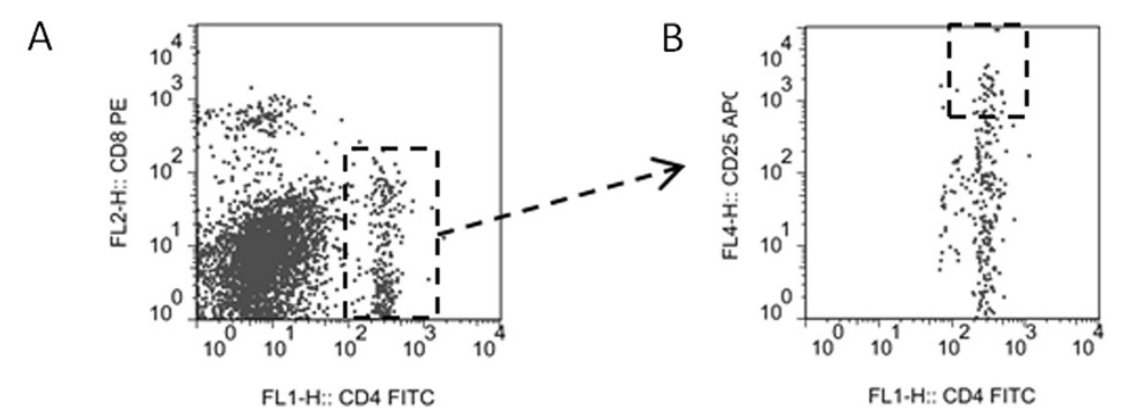

C

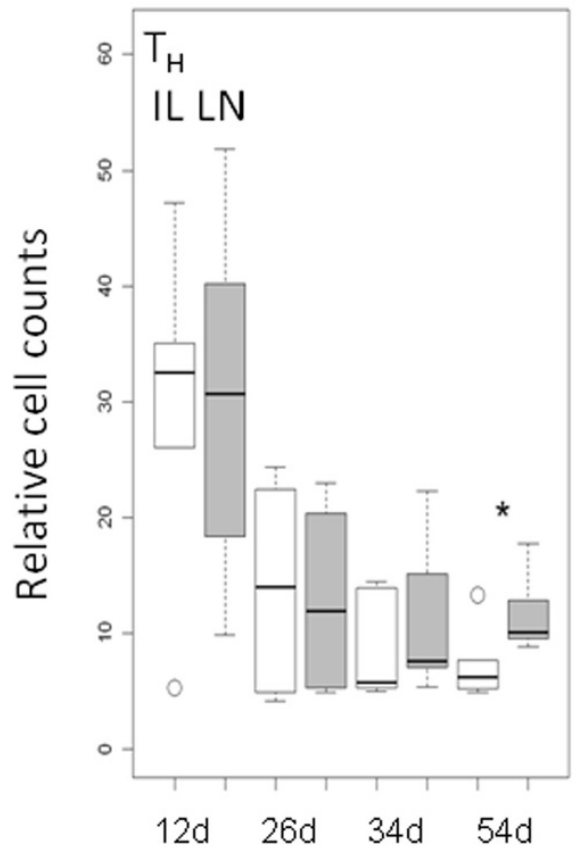

$E$

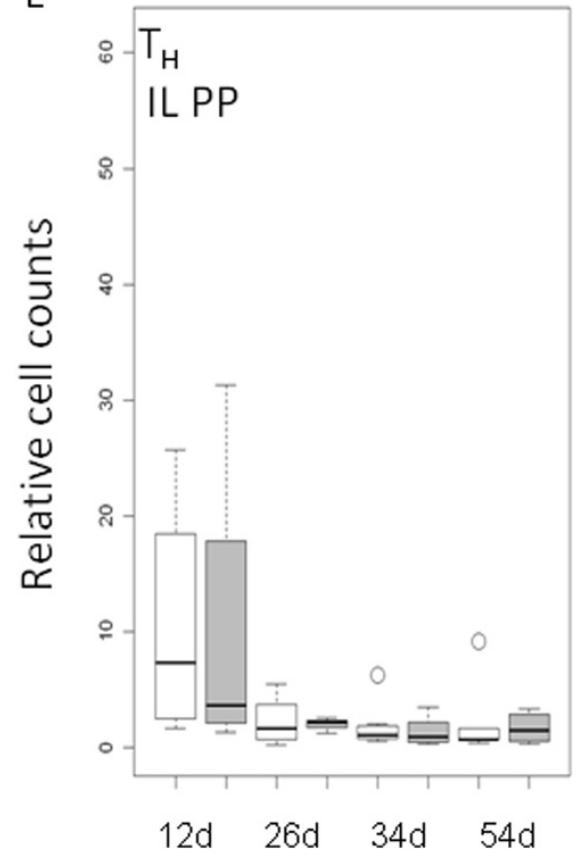

D
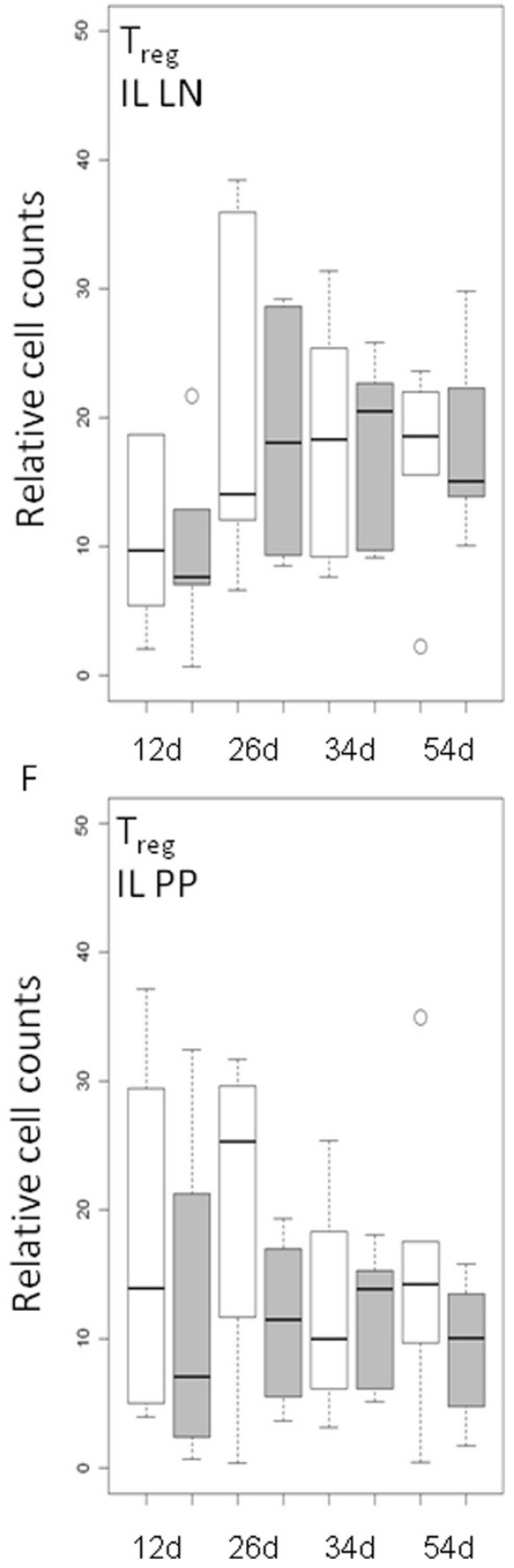

Figure 5 (See legend on next page.) 
(See figure on previous page.)

Figure 5 Relative cell counts of $C D 4^{+} C D 8^{-} T$ helper cells $\left(T_{H}\right)$ and $C D 4^{+} C D 25^{\text {hi }} T$ regulatory helper $\left(T_{\text {reg }}\right)$ cell subpopulation in piglets of the probiotic ( $n=6$ per time point, grey boxes) and the control group ( $n=6$ per time point, white boxes) at different days of life. Cell counts are given either for $T_{H}$ cells as counts relative to the total number of living lymphocytes or for the $T_{\text {regs }}$ as counts relative to the total number of $T_{H}$ cells. A) and $\mathbf{B}$ ) show the flow cytometry dot plots of one representative piglet. The marked population was considered as A) $T_{H}$ and B) $T_{\text {reg }}$ cells. C) $T_{H}$ cells and D) $T_{\text {reg }}$ cells in ileal lymph nodes (IL LN). E) $T_{H}$ cells and F) $T_{\text {reg }}$ cells in continuous ileal Peyer's Patch (IL PP). A t-test indicated significant differences between the feeding groups in the ileal lymph nodes at 54 days of age $\left({ }^{*} 0.01<p<0.05\right)$.

interaction [36] or clearing of infected cells by cytotoxic $\mathrm{T}$ cells [37]. We found especially in the youngest piglets (d12) significantly increased relative percentages of CD8 $\beta$ positive $\mathrm{T}$ cells in the probiotic group, compared to the control group (Figure 4). It is described that nearly all of the $C D 8 \beta^{+} \mathrm{T}$ cells belong to the $\mathrm{CD} 4^{+} \mathrm{CD} 8 \alpha^{\text {hi }}$ fraction which contains cytolytic T lymphocytes [38-40]. They recognize foreign antigens in a MHC class I-restricted manner and respond to the antigenic stimulation via proliferating, killing of the target cell, and secreting interferon $\gamma$ and tumour necrosis factor $\alpha$ [41]. This cell population is suggested to be crucial for clearing of rotavirus A [19]. As the rotavirus A infection occurred later and less severe in the probiotic group, this observation may indicate an early immune stimulation in this group, which might be advantageous against the rotavirus A infection. By analysing $\mathrm{CD}^{+} \mathrm{T}$ helper cells, a significant increase was observed in the probiotic group only at the latest time point (day 54 ). As the $\mathrm{T}_{\text {reg }}$ cell frequency was decreased at the same time-point, this increase is probably caused by proinflammatory $\mathrm{CD}^{+}{ }^{+} \mathrm{T}$ helper cell subtypes. This assumption has to be confirmed in future studies. As the significant $\mathrm{CD}^{+}{ }^{+} \mathrm{T}$ helper cell increase was only detected at the end of the study, a longer monitoring time should also be scheduled in those studies.

With respect to the experimental model used in the present study, it is possible that other factors that were not taken into consideration or analyzed could have influenced the outcome. As the pigs were naturally infected, random differences regarding virus infections and specific immunity against viruses at the beginning of the experiment cannot be ruled out. The present study points out that feeding of pigs with the probiotic bacterium Enterococcus faecium NCIMB 10415 shows no general effects on enteric virus infections, but that excretion of specific virus types may be affected. We suggest rotavirus $\mathrm{A}$ and $\mathrm{AstV}$ as targets of E. faecium. A possible protective mechanism could be the early activation of cytotoxic $\mathrm{T}$ cells through the probiotic. Therefore, rotavirus $A$ and $A s t V$ infections should be investigated in future studies in more controlled and longer-termed experimental animal studies as well as cell culture-based experiments to further elucidate the specific mechanisms of action.

\section{Additional files}

Additional file 1: Table S1. Primary and secondary antibodies (AB) used for flow cytometry staining.

Additional file 2: Table S2. Sequences of primers and probes for real-time RT-PCR.

Additional file 3: Figure S1. Body weight difference between piglets infected $(n=9)$ and not infected $(n=39)$ with rotavirus A.

Additional file 4: Figure S2. Absolute cell counts in the peripheral blood mononuclear cell (PBMC) population in piglets of the probiotic ( $n=6$ per time point, grey boxes) and the control group ( $n=6$ per time point, white boxes) at different days of age.

A) Absolute lymphocyte number in blood obtained by hemogram and B) absolute cell counts of $\mathrm{B}$ cells expressing $\mathrm{CD} 21^{+} \mathrm{MHCI}{ }^{+}$. Absolute cell counts are calculated from the absolute lymphocyte number in blood.

Additional file 5: Figure S3. Immune staining of different T cell populations in the ileal lymph nodes of one representative piglet. The cells are within a lymphocyte gate regarding their forward sightward scatter signal and were checked for cell death by PI staining in a prior gating step. The $x$ and $y$ axes show the intensity of fluorescent signals of PE labeled to CD8 on the $y$ axes and FITC labeled to CD4 on the $x$ axes (A). Framed cells populations in A) were further analyzed in B) and the $y$ axes show the intensity fluorescent signal of APC labeled to CD25. All lymphocytes for the same sample as shown in A) and B) for the fluorescent signals of PE were labeled to CD25 on the $y$ axes and FITC labeled to CD4 on the $x$ axes (C). Framed cells in C) were further analyzed in D) and the $x$ axes show the fluorescent signal of APC labeled to the transcription factor (TF) Foxp3.

Additional file 6: Table S3. Results of an ANOVA based on the model: \#Cells $\sim$ Tissue + age + group + sex + Tissue*age + Tissue*group + Tissue*sex. Additional file 7: Table S4. Results of $T$ tests for different cell types which reached in a former performed ANOVA a significant level. The $T$ test was carried out between the two feedings groups at the different sampling time points in blood (BL PBMC), ileal lymph nodes (IL LN), ileal Peyer's Patch (IL PP) and jejunal lymph nodes (Je LN).

\section{Competing interests}

The study was funded by the Deutsche Forschungsgemeinschaft (DFG) within the Collaborative Research Group (SFB, Sonderforschungsbereich) 852 "Nutrition and intestinal microbiota - host interactions in the pig". The authors are solely responsible for the data and do not represent any opinion of neither the DFG nor other public or commercial entity. None of the authors of this paper has a financial or personal relationship with other people or organizations that could inappropriately influence or bias the content of the paper.

\section{Authors' contributions}

SK carried out the sampling, detection and characterization of lymphocyte populations and drafted the manuscript. PM carried out the sampling, carried out the detection of the enteric viruses and the ELISA measurements and drafted the manuscript. JA performed statistical analysis. MS helped to carried out the sampling, detection and characterization of lymphocyte populations and contributed to writing the final version of the manuscript. RP performed the animal trial and drafted the manuscript. MFGS conceived of the study and contributed to writing the final version of the manuscript. $G A B$ conceived of the study and contributed to the final version of the 
manuscript. LST carried out the sampling, detection and characterization of lymphocyte populations and drafted the manuscript. RJ conceived of the study and contributed to the final version of the manuscript. All authors read and approved the final manuscript.

\section{Acknowledgments}

We thank A. Bosch (University of Barcelona, Barcelona, Spain) for providing positive controls for astrovirus- and EMCV-PCR assays. The study was funded by the Deutsche Forschungsgemeinschaft (DFG) through grant SFB 852/1.

\section{Author details}

${ }^{1}$ Breeding Biology and Molecular Genetics, Humboldt-Universität zu Berlin, Invalidenstraße 42, D-10115 Berlin, Germany. ${ }^{2}$ Federal Institute for Risk Assessment, Max-Dohrn-Str. 8-10, 10589 Berlin, Germany. ${ }^{3}$ Veterinary Virology, Freie Universität, Philippstraße 13, D-10115 Berlin, Germany. ${ }^{4}$ Animal Nutrition, Freie Universität Berlin, Königin-Luise-Str. 49, D-14195 Berlin, Germany. ${ }^{5}$ Veterinary Immunology and Molecular Biology, Freie Universität, Philippstraße 13, D-10115 Berlin, Germany.

Received: 24 February 2012 Accepted: 09 July 2012

Published: 27 July 2012

\section{References}

1. Casey PG, Gardiner GE, Casey G, Bradshaw B, Lawlor PG, Lynch PB, Leonard FC, Stanton C, Ross RP, Fitzgerald GF, Hill C: A five-strain probiotic combination reduces pathogen shedding and alleviates disease signs in pigs challenged with Salmonella enterica serovar typhimurium. App/ Environ Microbiol 2007, 73:1858-1863.

2. Konstantinov SR, Smidt H, Akkermans AD, Casini L, Trevisi P, Mazzoni M, De Filippi S, Bosi P, de Vos WM: Feeding of Lactobacillus sobrius reduces Escherichia coli F4 levels in the gut and promotes growth of infected piglets. FEMS Microbiol Ecol 2008, 66:599-607.

3. Daudelin JF, Lessard M, Beaudoin F, Nadeau E, Bissonnette N, Boutin Y Brousseau JP, Lauzon K, Fairbrother JM: Administration of probiotics influences F4 (K88)-positive enterotoxigenic Escherichia coli attachment and intestinal cytokine expression in weaned pigs. Vet Res 2011, 42:69.

4. Taras D, Vahjen W, Simon O: Probiotics in pigs - modulation of their intestinal distribution and of their impact on health and performance. Livestock Sci 2007, 108:229-231.

5. Martella V, Banyai K, Matthijnssens J, Buonavoglia C, Ciarlet M: Zoonotic aspects of rotaviruses. Vet Microbiol 2010, 140:246-255.

6. Aggarwal R, Naik S: Epidemiology of hepatitis E: current status. J Gastroenterol Hepatol 2009, 24:1484-1493.

7. Meng XJ: From barnyard to food table: the omnipresence of hepatitis $E$ virus and risk for zoonotic infection and food safety. Virus Res 2011, 161:23-30.

8. Billinis C, Paschaleri-Papadopoulou E, Psychas V, Vlemmas J, Leontides S, Koumbati M, Kyriakis SC, Papadopoulos O: Persistence of encephalomyocarditis virus (EMCV) infection in piglets. Vet Microbiol 1999, 70:171-177

9. Koenen F, De Clercq K, Lefebvre J, Strobbe R: Reproductive failure in sows following experimental infection with a Belgian EMCV isolate. Vet Microbiol 1994, 39:111-116.

10. Weizman Z, Asli G, Alsheikh A: Effect of a probiotic infant formula on infections in child care centers: comparison of two probiotic agents. Pediatrics 2005, 115:5-9.

11. Szajewska H, Kotowska M, Mrukowicz JZ, Armanska M, Mikolajczyk W: Efficacy of Lactobacillus GG in prevention of nosocomial diarrhea in infants. J Pediatr 2001, 138:361-365.

12. Isolauri $E$, Juntunen $M$, Rautanen $T$, Sillanaukee $P$, Koivula $T$ : $A$ human Lactobacillus strain (Lactobacillus casei sp strain GG) promotes recovery from acute diarrhea in children. Pediatrics 1991, 88:90-97.

13. Buydens P, Debeuckelaere S: Efficacy of SF 68 in the treatment of acute diarrhea. A placebo-controlled trial. Scand J Gastroenterol 1996, 31:887-891.

14. Zhang J, Deng J, Wang Z, Che C, Li YF, Yang Q: Modulatory effects of Lactobacillus salivarius on intestinal mucosal immunity of piglets. Curr Microbiol 2011, 62:1623-1631.

15. Scharek L, Guth J, Filter M, Schmidt MF: Impact of the probiotic bacteria Enterococcus faecium NCIMB 10415 (SF68) and Bacillus cereus var. toyoi
NCIMB 40112 on the development of serum IgG and faecal lgA of sows and their piglets. Arch Anim Nutr 2007, 61:223-234.

16. Scharek L, Guth J, Reiter K, Weyrauch KD, Taras D, Schwerk P, Schierack P Schmidt MF, Wieler LH, Tedin K: Influence of a probiotic Enterococcus faecium strain on development of the immune system of sows and piglets. Vet Immunol Immunopathol 2005, 105:151-161.

17. Shu Q, Qu F, Gill HS: Probiotic treatment using Bifidobacterium lactis HN019 reduces weanling diarrhea associated with rotavirus and Escherichia coli infection in a piglet model. J Pediatr Gastroenterol Nutr 2001, 33:171-177.

18. Zhang W, Azevedo MS, Gonzalez AM, Saif LJ, Van Nguyen T, Wen K, Yousef $A E$, Yuan L: Influence of probiotic Lactobacilli colonization on neonatal $B$ cell responses in a gnotobiotic pig model of human rotavirus infection and disease. Vet Immunol Immunopathol 2008, 122:175-181.

19. Desselberger $\mathrm{U}$, Huppertz $\mathrm{HI}$ : Immune responses to rotavirus infection and vaccination and associated correlates of protection. J Infect Dis 2011, 203:188-195.

20. Fu ZF, Hampson DJ, Wilks CR: Transfer of maternal antibody against group A rotavirus from sows to piglets and serological responses following natural infection. Res Vet Sci 1990, 48:365-373.

21. Pollmann M, Nordhoff M, Pospischil A, Tedin K, Wieler LH: Effects of a probiotic strain of Enterococcus faecium on the rate of natural chlamydia infection in swine. Infect Immun 2005, 73:4346-4353.

22. Szabo I, Wieler LH, Tedin K, Scharek-Tedin L, Taras D, Hensel A, Appel B, Noeckler K: Influence of a Probiotic Strain of Enterococcus faecium on Salmonella enterica Serovar Typhimurium DT104 Infection in a Porcine Animal Infection Model. Appl Environ Microbiol 2009, 75:2621-2628.

23. Martin LPR, Kröger S, Goodarzi Boroojeni F, Vahjen W, Neumann K, Van Kessel AG, Zentek J: Influence of age and Enterococcus faecium NCIMB 10415 on development of small intestinal digestive physiology in piglets. Anim Feed Sci Technol 2012, 175:65-75.

24. Mafamane H, Szabo I, Schmidt MF, Filter M, Walk N, Tedin K, Scharek-Tedin $L$ : Studies on the effect of an Enterococcus faecium probiotic on $T$ cell populations in peripheral blood and intestinal epithelium and on the susceptibility to Salmonella during a challenge infection with Salmonella Typhimurium in piglets. Arch Anim Nutr 2011, 65:415-430.

25. Jothikumar N, Cromeans TL, Robertson BH, Meng XJ, Hill VR: A broadly reactive one-step real-time $R T-P C R$ assay for rapid and sensitive detection of hepatitis E virus. J Virol Methods 2006, 131:65-71.

26. Pang XL, Lee B, Boroumand N, Leblanc B, Preiksaitis JK, Yu Ip CC: Increased detection of rotavirus using a real time reverse transcription-polymerase chain reaction (RT-PCR) assay in stool specimens from children with diarrhea. J Med Virol 2004, 72:496-501.

27. Loisy F, Atmar RL, Guillon P, Le Cann P, Pommepuy M, Le Guyader FS: Realtime RT-PCR for norovirus screening in shellfish. J Virol Methods 2005, 123:1-7

28. Pinto RM, Costafreda Ml, Bosch A: Risk assessment in shellfish-borne outbreaks of hepatitis A. Appl Environ Microbiol 2009, 75:7350-7355.

29. Noel JS, Lee TW, Kurtz JB, Glass Rl, Monroe SS: Typing of human astroviruses from clinical isolates by enzyme immunoassay and nucleotide sequencing. J Clin Microbiol 1995, 33:797-801.

30. Schielke A, Filter M, Appel B, Johne R: Thermal stability of hepatitis E virus assessed by a molecular biological approach. Virol J 2011, 8:487.

31. Ivec M, Botic T, Koren S, Jakobsen M, Weingartl H, Cencic A: Interactions of macrophages with probiotic bacteria lead to increased antiviral response against vesicular stomatitis virus. Antiviral Res 2007, 75:266-274.

32. Kritas SK, Morrison RB: Effect of orally administered Lactobacillus casei on porcine reproductive and respiratory syndrome (PRRS) virus vaccination in pigs. Vet Microbiol 2007, 119:248-255.

33. Luo Z, Roi S, Dastor M, Gallice E, Laurin MA, L'Homme Y: Multiple novel and prevalent astroviruses in pigs. Vet Microbio/ 2011, 149:316-323.

34. Ulloa JC, Gutierrez MF: Genomic analysis of two ORF2 segments of new porcine astrovirus isolates and their close relationship with human astroviruses. Can J Microbiol 2010, 56:569-577.

35. Grandy G, Medina M, Soria R, Teran CG, Araya M: Probiotics in the treatment of acute rotavirus diarrhoea. A randomized, double-blind, controlled trial using two different probiotic preparations in Bolivian children. BMC Infect Dis 2010, 10:253.

36. Quigley EM: Probiotics in gastrointestinal disorders. Hosp Pract (Minneap) 2010, 38:122-129. 
37. Boirivant $M$, Strober $W$ : The mechanism of action of probiotics. Curr Opin Gastroenterol 2007, 23:679-692.

38. Gerner W, Kaser T, Saalmuller A: Porcine T lymphocytes and NK cells-an update. Dev Comp Immunol 2009, 33:310-320.

39. Saalmuller A, Kuebart G, Hollemweguer E, Chen Z, Nielsen J, Zuckermann F, Haverson K: Summary of workshop findings for porcine T-lymphocytespecific monoclonal antibodies. Vet Immunol Immunopathol 2001, 80:35-52.

40. Pauly T, Weiland E, Hirt W, Dreyer-Bux C, Maurer S, Summerfield A, Saalmuller A: Differentiation between MHC-restricted and non-MHCrestricted porcine cytolytic T lymphocytes. Immunology 1996, 88:238-246.

41. Piriou L, Chevallier S, Hutet E, Charley B, Le Potier MF, Albina E: Humoral and cell-mediated immune responses of $\mathrm{d} / \mathrm{d}$ histocompatible pigs against classical swine fever (CSF) virus. Vet Res 2003, 34:389-404.

doi:10.1186/1297-9716-43-58

Cite this article as: Kreuzer et al.: Feeding of the probiotic bacterium Enterococcus faecium NCIMB 10415 differentially affects shedding of enteric viruses in pigs. Veterinary Research 2012 43:58.

\section{Submit your next manuscript to BioMed Central and take full advantage of:}

- Convenient online submission

- Thorough peer review

- No space constraints or color figure charges

- Immediate publication on acceptance

- Inclusion in PubMed, CAS, Scopus and Google Scholar

- Research which is freely available for redistribution 